\title{
Efeito de diferentes tratamentos de polinização em berinjela em casa de vegetação
}

\section{Effect of different pollination treatment in eggplant in a greenhouse}

\author{
Marília Araújo da Silva ${ }^{1}$, Francisco de Assis de Oliveira ${ }^{2}$, Michael Hrncir $^{3}$
}

Resumo: O presente trabalho objetivou avaliar a influência de diferentes tipos de polinização na quantidade e qualidade de berinjela (Solanum melongena) cultivada em casa de vegetação. A pesquisa foi realizada em uma casa de vegetação localizada na Universidade Federal Rural do Semiárido (UFERSA), Mossoró/RN. Foram utilizadas duas colônias de Scaptotrigona sp. Para verificar os requerimentos de polinização foram realizados quatro tratamentos: polinização livre, autopolinização, polinização manual por vibração e polinização cruzada manual, comparando a quantidade e qualidade dos frutos obtidos de cada tratamento, como peso, comprimento, circunferência e número de sementes produzidas. O tratamento de polinização cruzada manual (PCM) apresentou os maiores valores em relação a número de frutos produzidos $(26,67 \%)$ e com maior número de sementes $\left(1^{\circ}\right.$ corte: $3,2 \pm 10,12 ; 2^{\circ}$ corte: $26,7 \pm 27,91 ; 3^{\circ}$ corte: $\left.103,4 \pm 21,79\right)$ quando comparados com os demais tratamentos, entretanto o peso, comprimento e circunferência dos frutos não diferiram entre os tratamentos. A Scaptotrigona sp. não visitou as flores durante o período em que foram mantidas na casa de vegetação, porém são necessários mais estudos para determinar o verdadeiro potencial de Scaptotrigona sp. como polinizador de culturas em casa de vegetação.

Palavras-chaves: Solanum melongena. Ambiente protegido. Abelha sem ferrão.

Abstract: This study aimed was to evaluate the influence of different types of pollination in the quantity and quality of eggplant grown under greenhouse conditions and the behavior of Scaptotrigona sp. in a greenhouse. The survey was conducted in a greenhouse located on the Universidade Federal do Semiárido (UFERSA), Mossoró/RN. They used two colonies of Scaptotrigona sp. To check the pollination requirements in both cultures four treatments were performed: open pollinated, selfpollination, manual pollination by vibration and manual cross-pollination by comparing the quantity and quality of fruit from each treatment, such as weight, length and circumference and number of seeds produced. The manual cross-pollination treatment $(\mathrm{PCM})$ had the highest values regarding the number of fruit $(26,67 \%)$ and more seeds $\left(1^{\circ}\right.$ corte: $3,2 \pm 10,12 ; 2^{\circ}$ corte: $26,7 \pm 27,91 ; 3^{\circ}$ corte: $\left.103,4 \pm 21,79\right)$ when compared to other treatments, however the weight, length and circumference of the fruits did not differ between treatments. The Scaptotrigona sp. did not visit flowers during the period in which they were kept in the greenhouse however more studies are needed to determine the true potential of Scaptotrigona sp. as pollinator of crops in the greenhouse.

Key words: Solanum melongena. Protected environment. Stingless bee.

\footnotetext{
*Autor para correspondência

Recebido para publicação em 02/11/2015; aprovado em 10/03/2015

${ }^{1}$ Mestre em Ecologia e Conservação, Universidade Federal Rural do Semiárido - UFERSA, Mossoró/RN; E-mail: lilaaraujo90@ @otmail.com.

${ }^{2}$ Professor do Departamento de Ciências Ambientais e Tecnológicas, Universidade Federal Rural do Semiárido - UFERSA, E-mail: thikãoamigão@ufersa.br

${ }^{3}$ Professor do Departamento de Ciências Animais, Universidade Federal Rural do Semiárido - UFERSA, E-mail: michael@ufersa.br
} 


\section{INTRODUÇÃO}

A ausência de agentes polinizadores é um problema sério para cultivos em casa de vegetação. Por um lado, esses locais oferecem proteção às plantas, sendo assim possível cultivar o ano todo e independente das condições ambientais (HEARD, 1999). Entretanto, a deficiência na polinização devido à ausência de polinizadores no ambiente fechado pode levar a uma redução na quantidade e qualidade de frutos (HEARD, 1999).

Entre as plantas cultivadas em casa de vegetação, várias espécies da família Solanaceaes (tomate, berinjela, pimentão, pimenta, entre outras), apesar de serem autocompatíveis, mas dependentes de agentes de polinização, dependem de abelhas capazes de realizar a vibração das anteras da flor, o que é essencial para a liberação do pólen e consequente polinização da cultura (NUNES-SILVA et al, 2010). Este tipo de polinização é denominado de polinização por vibração ou "buzz pollination" (BUCHMANN; HURLEY, 1978). Espécies de abelhas capazes de realizar a vibração, tais como algumas espécies de abelhas solitárias, mamangávas (Apidae, Bomibini) e abelhas sem ferrão (Apidae, Meliponini), são consideradas polinizadores eficientes de várias solanáceas cultivadas em casa de vegetação (NUNES-SILVA et al, 2010).

Uma das vantagens da introdução de abelhas sem ferrão em casa de vegetação está relacionado a algumas características que elas apresentam como a ausência de ferrão funcional (MICHENER, 2013), o que proporciona uma maior segurança ao produtor (AMANO, 2000), além de uma menor amplitude de voo de forrageamento, a perenidade das colônias (SLAA et al, 2000; CRUZ; CAMPOS, 2009; MEYRELLES, 2013), constância floral, forrageamento contínuo e grandes reservas de alimento dentro dos ninhos (HEARD, 1999). Porém, ainda são necessários mais estudos, já que os trabalhos abordando este tema são limitados. Além disso, experimentos para avaliar a eficiência da produção resultante da polinização por abelhas sem ferrão e para melhorar as técnicas de gestão das colônias são de extrema importância para que as mesmas possam ser utilizadas de forma satisfatória (AMANO, 2000).

Vários estudos têm mostrado a potencialidade do uso de várias espécies desse grupo de abelhas eussociais em casa de vegetação no cultivo de solanáceas, como berinjela (BISPO DOS SANTOS, 2008; NUNES-SILVA et al., 2013), pimentão (ROSELINO, 2005; CRUZ et al., 2005; ROSELINO et al, 2010; SILVA et al., 2005), tomate (MEYRELLES, 2013; CAUICH et al., 2004; BISPO DOS SANTOS, 2008; DEL SARTO, 2005) e pimenta (PALMA et al., 2008; CRUZ, 2009; NASCIMENTO et al., 2012). Em todos estes estudos, a polinização por abelhas sem ferrão levou a um aumento significativo na quantidade dos frutos produzidos e na sua qualidade em relação a diversas variáveis como tamanho, peso, número de sementes e menor número de frutos deformados.

Entretanto, apesar das inúmeras vantagens, um dos problemas que podem dificultar a permanência das colônias no ambiente protegido é a temperatura elevada no interior da casa de vegetação (MEYRELLES, 2013). Isto torna-se ainda mais sério quando analisamos a região semiárida no nordeste brasileiro, a qual é caracterizada por temperaturas ambientais anuais elevadas com a temperatura média mensal variando de 26 a $34{ }^{\circ} \mathrm{C}$ (MOURA et al., 2007), resultando em temperaturas ainda mais elevadas no interior das casas de vegetação. Outras técnicas, como a polinização manual ou por meio de vibradores elétricos, podem ser utilizadas para suprirem a ausência de polinizadores nesses locais, porém pode levar a um aumento no custo da produção, tornando-a economicamente inviável (FREE, 1993). Entretanto alguns estudos mostram sucesso no uso de abelhas sem ferrão em casas de vegetação na Caatinga, como na polinização de pimentão por M. subnitida (CRUZ et al, 2005; SILVA et al, 2005) e de mini melancia por M. subnitida e Scaptotrigona sp. (BOMFIM et al, 2014).

Deste modo, o presente trabalho teve como objetivo avaliar a influência de diferentes tipos de polinização (autopolinização, polinização livre, polinização por vibração manual e polinização cruzada manual) na quantidade e qualidade de berinjela (Solanum melongena) cultivada em casa de vegetação na região do Semiárido Brasileiro.

\section{MATERIAL E MÉTODOS}

\section{Localização e período do experimento}

O presente estudo foi desenvolvido no período de 05 de setembro de 2014 a 03 de março de 2015, em uma casa de vegetação localizada no Campus Oeste da Universidade Federal Rural do Semiárido - UFERSA, em Mossoró, Rio Grande do Norte, Brasil ( $5^{\circ} 11^{\prime} \mathrm{S}$ e $37^{\circ} 20^{\prime} \mathrm{W}$ e altitude de 18 $\mathrm{m})$. A casa de vegetação utilizada apresenta cobertura de polietileno de baixa densidade transparente com $0,10 \mathrm{~mm}$ de espessura, tratada contra a ação de raios ultravioletas e em formato tipo arco, com 7,0 $\mathrm{m}$ de largura e $21 \mathrm{~m}$ de comprimento. As paredes laterais e frontais são confeccionadas com telas anti-afídeos e rodapé de 0,30 m em concreto armado.

\section{Manutenção e treinamento de abelhas na casa de vegetação}

Para avaliar a eficiência de abelhas sem ferrão como polinizadores de culturas de solanáceas em casa de vegetação, foi avaliada a polinização de berinjela (Solanum melongena) por Scaptotrigona sp., espécie a ser identificada, proveniente de Crato/CE. Neste experimento foram utilizadas duas colônias de Scaptotrigona sp. Todas as colônias foram mantidas em caixas de madeira na Fazenda Experimental Rafael Fernandes da UFERSA e transferidas para o local dos experimentos no período de florescimento da respectiva cultura, sendo mantidas fechadas por cerca de 3 dias antes de sua abertura.

Durante todos os experimentos, algumas herbáceas ornamentais não identificadas adquiridas no mercado local foram colocadas na casa de vegetação para fornecimento de néctar, uma vez que as flores de berinjela não disponibilizam este recurso. Além disso, foram mantidas algumas plantas nativas as quais já existiam dentro da casa de vegetação, como quebra-panela (Alternanthera tenella Colla), chanana (Turnera subulata $\mathrm{Sm}$.), santa-luzia (Commelina erecta L.), jetirana-de-mocó (Merremia aegyptia (L.) Urb), e a Amargosa (Marsypianthes chamaedrys (varl) Kuntze).

Aliado a isto, foram colocados alimentadores artificiais contendo xarope (uma mistura de açúcar e água, na proporção de 1:1, e essência de pau rosa) no interior da casa de vegetação durante todo o período do estudo. O xarope era 
reposto diariamente ou quando necessário. Imediatamente após a instalação e abertura das colônias realizou-se o treinamento das abelhas para essa fonte externa de xarope. $\mathrm{O}$ treinamento consistia em colocar gotas de xarope na entrada das colônias e esperar que as abelhas se aproximassem. Uma vez que as abelhas começaram a coletar o xarope, a fonte foi distanciada cada vez mais da colônia. Recipientes contendo água foram dispostos próximos às colônias, para servirem como fonte de água.

A temperatura no interior da casa de vegetação foi medida utilizando um data logger $\mathrm{HOBO}{ }^{\circledR} \mathrm{U} 12-008$ com quatro sensores de temperatura T1MC50, sendo um colocado no exterior e outro no interior da casa de vegetação. Todos os sensores foram programados para coletarem dados simultaneamente a cada 5 minutos durante todo o período que as colônias permaneceram na casa de vegetação. Os dados armazenados foram transferidos para um PC utilizando o software $\mathrm{HOBO}$ ware 3.0.0 e posteriormente transferidos para o software Microsoft Excel.

\section{Polinização de berinjela}

O estudo foi realizado de 05 de setembro de 2014 a 03 de março de 2015, período este que corresponde desde a semeadura até a análise de produção. As mudas foram produzidas em bandejas de isopor com 200 células e transplantadas para baldes de 20 litros, cerca de 30 dias após a semeadura. Foram utilizadas 20 plantas de berinjela (Solanum melongena), variedade embu. Após o transplantio, as mudas foram irrigadas diariamente com o sistema de irrigação da própria casa de vegetação, sendo que o tempo e o número de irrigações diárias foram alterados durante o experimento dependendo da necessidade das plantas. A irrigação foi realizada por um sistema de gotejamento localizado composto por mangueiras fixas e por gotejadores espaçados em aproximadamente $50 \mathrm{~cm}$. Para a fertirrigação, foi adicionado o adubo dissolvido na própria caixa dágua e distribuído para as plantas através do sistema de irrigação por gotejamento da casa de vegetação. As quantidades de nutrientes foram adaptadas de TRANI et al (2011). Após o início da floração foram introduzidas duas colônias de Scaptotrigona sp.

\section{Tratamentos de polinização}

Visando conhecer os requerimentos e a eficiência de polinização, cinco tratamentos foram realizados durante o florescimento da cultura. As flores foram marcadas com linha de algodão, sendo que cada tratamento recebeu uma cor diferente para posterior identificação. As flores foram marcadas de modo aleatório de acordo com a disponibilidade de botões florais em cada planta e foram retirados todos os botões florais próximos ao botão marcado, visando diminuir a competição por recursos:

I. Autopolinização (AP): para esse tratamento, 60 botões florais foram marcados com linha de algodão e protegidos com sacos de papel no dia anterior a sua antese, permanecendo ensacados por todo o momento em que as flores se encontraram abertas, visando impedir a ação de qualquer agente externo e, deste modo, verificar a capacidade da planta se autopolinizar.

II. Polinização por vibração manual (PVM): um total de 60 botões florais foram marcados e ensacados no dia anterior a sua antese. No dia seguinte, a vibração das anteras foi realizada utilizando-se uma escova de dentes elétrica, visando proporcionar a liberação do pólen e a autofecundação da cultura em estudo. As flores foram novamente ensacadas até a queda da flor ou vigamento do fruto.

III. Polinização cruzada manual (PCM): Foram marcados 60 botões florais. As flores a serem polinizadas foram marcadas com linha de algodão e ensacadas no dia anterior a antese, no dia seguinte, foram desensacadas e em seguida, retirou-se grãos de pólen oriundos de outra planta onde se encontrava a flor a ser polinizada e com um palito de dente colocou-se o pólen no estigma da flor a ser polinizada. Esse procedimento foi realizado entre 08:00 12:00 hs, utilizando a metodologia adaptada de Nunes-Silva (2011).

IV. Polinização livre (PL): com o objetivo de identificar o nível de polinização natural das flores, sem qualquer manipulação e com ação dos agentes polinizadores existentes, 60 botões florais foram marcados com linha de algodão no dia anterior ao da antese (abertura da flor) e acompanhados até a formação do fruto.

Os frutos colhidos de todos os tratamentos descritos acima foram analisados quanto a quatro variáveis:

a) Vingamento inicial e persistência dos frutos: foram feitas três observações após a realização dos tratamentos de polinização, assim como no momento da colheita para verificar os frutos que vingaram e persistiram até a coleta.

b) Massa dos frutos: quando ficaram maduros, os frutos de cada tratamento foram colhidos e pesados individualmente, com auxílio de uma balança com precisão de $1 \mathrm{mg}$.

c) Circunferência e comprimento dos frutos: após a pesagem foi utilizado um paquímetro com precisão de $1 \mathrm{~mm}$ para medir o comprimento de uma extremidade a outra (A) e uma fita métrica para medir a circunferência dos frutos de cada tratamento, obtendo-se três medidas: circunferência da extremidade basal (B); circunferência da região medial (C) e circunferência da extremidade apical (D) (BISPO DOS SANTOS, 2008) (Figura 1).

Figura 1: Indicações das medidas realizadas em fruto de berinjela, Solanum melongena: a) Comprimento de uma extremidade a outra; b) Circunferência da extremidade basal; c) Circunferência da região medial; d) Circunferência da extremidade apical

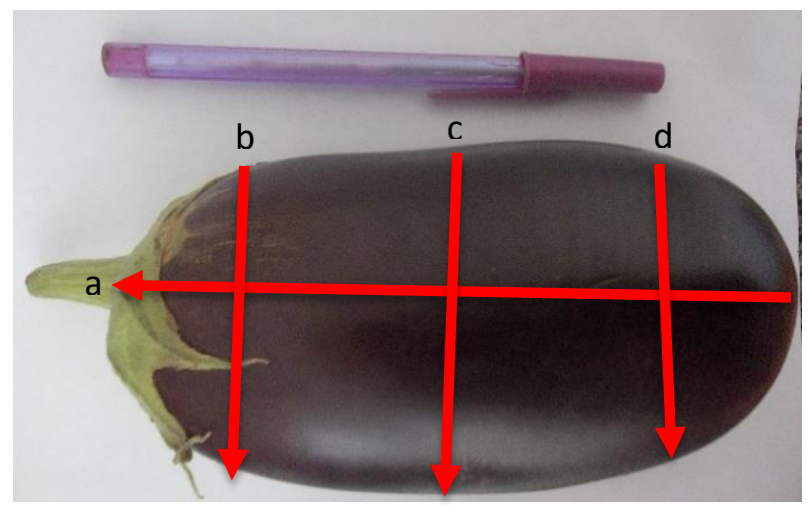

d) Número de sementes por fruto: Para a contagem das sementes de berinjela utilizou-se o seguinte método: foram retiradas três fatias de aproximadamente $1 \mathrm{~cm}$ de espessura de três regiões do fruto, sendo uma da extremidade basal, uma da região medial e outra da extremidade apical. 
Contou-se, então, o número de sementes visíveis dos dois lados de cada fatia (BISPO DOS SANTOS, 2008) (Figura 2).

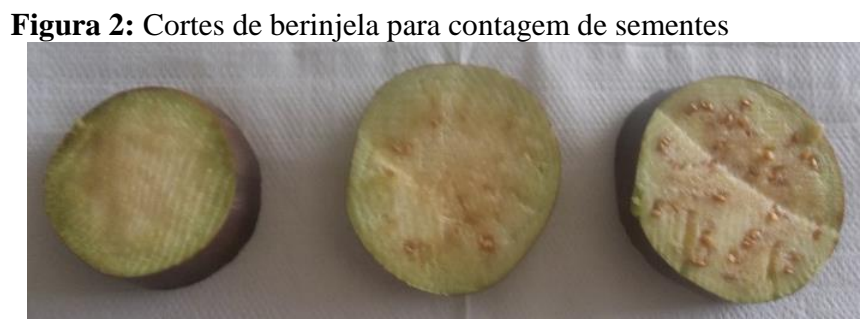

Os resultados foram analisados através do teste Teste Kruskal-Wallis One Way Analysis of Variance on Ranks com nível de significância de $\mathrm{P}<0,05$, comparando se houve diferença significativa entre as variáveis de cada tratamento.

\section{Análise estatística}

Os dados foram analisados utilizando o software SigmaPlot 12.5. Foram analisadas possíveis diferenças na temperatura média diária entre os ambientes diferentes através do Teste Kruskal-Wallis One Way ANOVA on Ranks (teste post-hoc, método de Dunn) com nível de significância de $\mathrm{P}<0,05$. O mesmo teste foi utilizado para comparar as características dos frutos provenientes dos diferentes tratamentos de polinização (peso, circunferência, comprimento e número de sementes).

\section{RESULTADOS E DISCUSSÃO}

\section{Temperatura durante os experimentos}

As temperaturas no interior e exterior da casa de vegetação apresentaram variações ao longo do dia. De modo geral, a temperatura aumentou gradativamente a partir das 7 horas. $\mathrm{O}$ pico de temperatura no ambiente externo $\left(36,6{ }^{\circ} \mathrm{C}\right)$ foi às 14 horas, já no interior da casa de vegetação $\left(36,3{ }^{\circ} \mathrm{C}\right)$ foi às 13 horas (Figura 3).

Figura 3: Temperatura média diária no interior e exterior da casa de vegetação

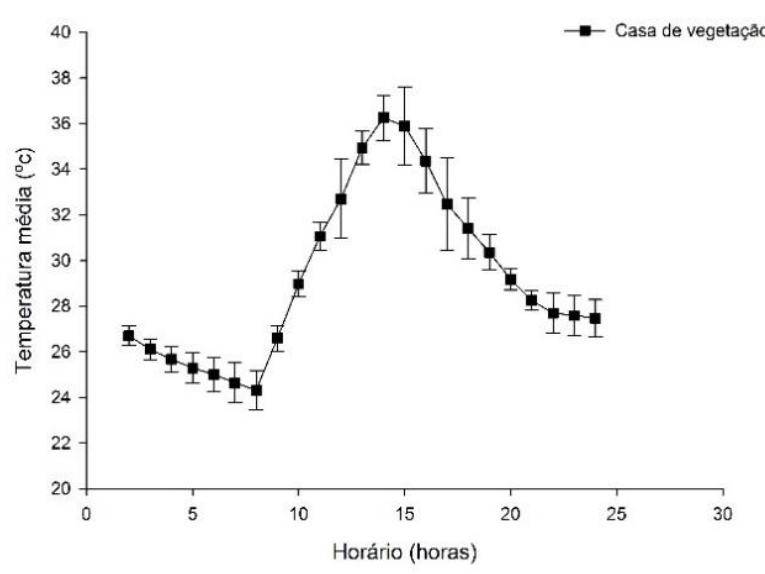

No presente trabalho, as colônias de Scaptotrigona sp. foram retiradas na $5^{\mathrm{a}}$ semana, não visitando as flores no tempo em que permaneceram no local. Estudos com $A$. mellifera no deserto de Sonora, mostraram que o forrageamento de pólen decresce em altas temperaturas ambientais (COOPER et al, 1985). A temperatura torácica das coletoras de pólen são significantemente maiores que as temperaturas torácicas de coletoras de água e néctar a $40^{\circ} \mathrm{C}$, sendo que estas preferem coletar pólen em temperaturas mais baixas do que aquelas que coletam néctar ou água, uma vez que estes são capazes de reduzir a temperatura do corpo através de resfriamento por evaporação dos líquidos que transportam (COOPER et al, 1985). Como as flores de berinjela apresentam apenas pólen, pode-se propor que talvez a alta temperatura no interior da casa de vegetação pode ter influenciado na coleta deste recurso pelas forrageadoras.

Além disso, a alta temperatura registrada pode ter levado a uma redução sucessiva no número de abelhas e de células de cria ao longo do período do estudo, tendo-se em vista que as colônias de Scaptotrigona sp. utilizadas nos experimentos, apresentavam inicialmente um grande número de indivíduos, o qual foi reduzido drasticamente ao longo do experimento. Em um experimento realizado na cidade de Londrina, no estado do Paraná, Macieira e Proni (2004) verificaram a capacidade de resistência a altas e baixas temperaturas em

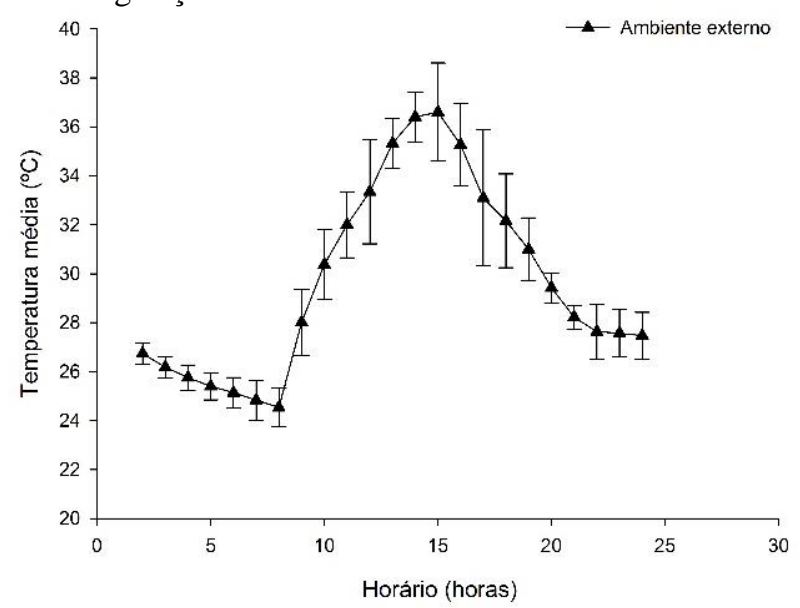

operárias de Scaptotrigona postica durante os períodos de verão e inverno, mostrando a relação entre mortalidade e temperatura e perceberam que em altas temperaturas houve $50 \%$ de mortalidade em $40^{\circ} \mathrm{C}$ no verão e em $39,5^{\circ} \mathrm{C}$ no inverno e $100 \%$ de mortalidade no limite de $41^{\circ} \mathrm{C}$ no verão e $40,5^{\circ} \mathrm{C}$ no inverno.

\section{Tratamentos de polinização com berinjela}

As forrageadoras de Scaptotrigona sp. não visitaram as flores de berinjela. Portanto, os resultados do tratamento de polinização livre (PL) se referem a uma polinização livre na ausência de polinizadores.

Em um estudo com berinjela polinizada por $M$. quadrifasciata, Bispo dos Santos (2008) observou poucos indivíduos visitando as flores de berinjela. Propõe-se que talvez as flores não sejam atrativas para a espécie em estudo, já que foram observadas abelhas nas folhas de berinjela e nas flores das plantas que foram utilizadas como fonte de néctar, mas nenhuma nas flores de berinjela.

Em seu trabalho Bartelli (2013) relatou que um dos problemas que podem ter dificultado a adaptação das Melipona quadrifasciata em um período curto pode estar relacionado a difusão dos raios solares e o bloqueio da radiação ultravioleta provocados pela cobertura plástica da casa de vegetação dificultando a orientação e identificação 
das flores pelas operárias. Desde modo, propôs que algumas mudanças estruturais nas casas de vegetação, assim como o aprimoramento das técnicas de manejo, poderiam melhorar o aproveitamento de abelhas sem ferrão na polinização de espécies vegetais cultivadas em ambientes protegidos (BARTELLI, 2013). Resultados semelhantes ao observado também foram descritos por Meyrelles (2013) em um estudo com tomate cereja em estufa utilizando a $M$. quadrifasciata, as quais não se adaptaram quando colocadas no interior da casa de vegetação, consequentemente não visitando as flores (MEYRELLES, 2013).

Em relação a produção de frutos de berinjela, houve diferença entre os tratamentos de autopolinização (AP), polinização livre (PL), polinização por vibração manual (PVM) e polinização cruzada manual (PCM). O tratamento de polinização livre não gerou frutos $(0 \%)$ e, consequentemente, foi eliminado da análise de dados. $O$ tratamento de autopolinização gerou apenas 1 fruto $(1,67 \%)$, e os tratamentos de polinização cruzada manual (16 frutos, $26,67 \%$ ) e de polinização por vibração manual (5 frutos, $8,33 \%$ ) também apresentaram uma taxa de frutificação baixa.

Os frutos dos tratamentos de polinização cruzada manual (PCM) proporcionou frutos com comprimento médio de $10,98 \pm 3,26 \mathrm{~cm}$ e peso médio de $233,65 \pm 98,30$ g. Já o tratamento de autopolinização apresentou o menor fruto medindo $8 \mathrm{~cm}$ de comprimento e pesando 95,09 g. O tratamento de polinização por vibração manual apresentou frutos com peso médio de 116,32 $\pm 59,08 \mathrm{~g}$ e comprimento médio de $9,86 \pm 1,76 \mathrm{~cm}$ (Figura 4 ). O peso e o comprimento não diferiram entre os tratamentos (teste post-hoc, método de Dunn, $\mathrm{P}>0,05)$.

Figura 4: Valores referentes ao peso e comprimento dos frutos de berinjela de cada tratamento. PCM=Polinização cruzada manual; PVM=Polinização por vibração manual; $\mathrm{AP}=$ Autopolinização. Asterisco indica diferença significativa entre os grupos (Kruskal Wallis One Way ANOVA: P < 0,001; teste post-hoc, método de Dunn, $\mathrm{P}<0,05$ ).

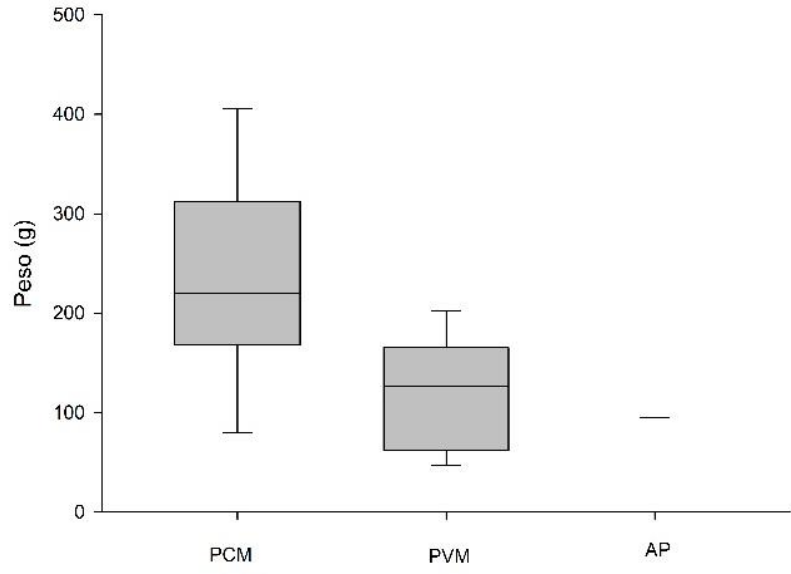

As circunferências dos frutos de polinização cruzada manual (PCM; extremidade basal: $19,55 \pm 2,80 \mathrm{~cm}$; região medial: $23,80 \pm 3,48 \mathrm{~cm}$; extremidade apical: 23,95 \pm $3,73 \mathrm{~cm}$ ), autopolinização (AP; extremidade basal: $14,96 \mathrm{~cm}$; região medial: $18,10 \mathrm{~cm}$; extremidade apical: $17,20 \mathrm{~cm}) \mathrm{e}$

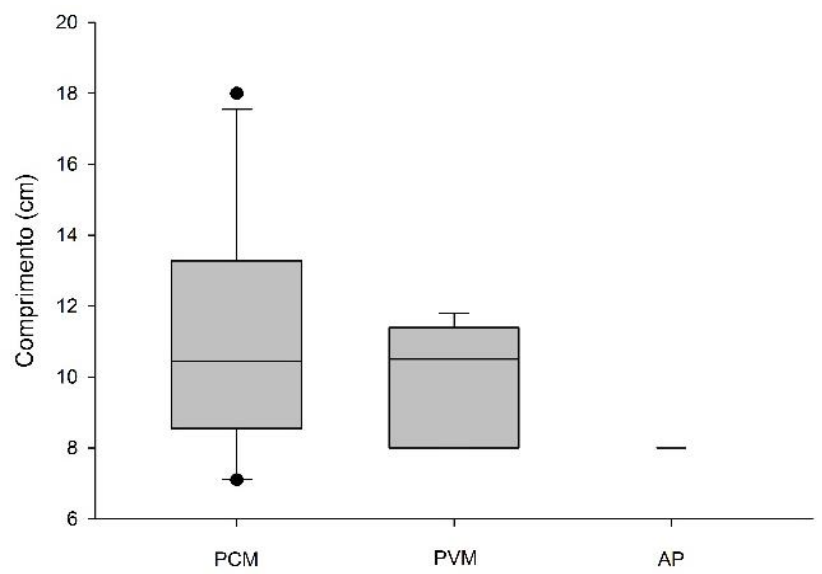

polinização por vibração manual (PVM; extremidade basal: $13,92 \pm 3,46 \mathrm{~cm}$; região medial: $18,60 \pm 4,02 \mathrm{~cm}$; extremidade apical: $18,54 \pm 3,97 \mathrm{~cm}$ ) não diferiram entre si (teste post-hoc, método de Dunn, $\mathrm{P}>0,05)$ (Figura 5).

Figura 5: Valores referentes as circunferências de 3 regiões da berinjela. EB: Circunferência da Extremidade basal; RM: Circunferência da Região Medial; EA: Circunferência da Extremidade Apical. PVM=Polinização por vibração manual; PCM=Polinização cruzada manual; $\mathrm{AP}=$ Autopolinização. Asterisco indica diferença significativa entre os grupos (Kruskal Wallis One Way ANOVA: $\mathrm{P}<0,001$; teste post-hoc, método de Dunn, $\mathrm{P}<0,05)$.

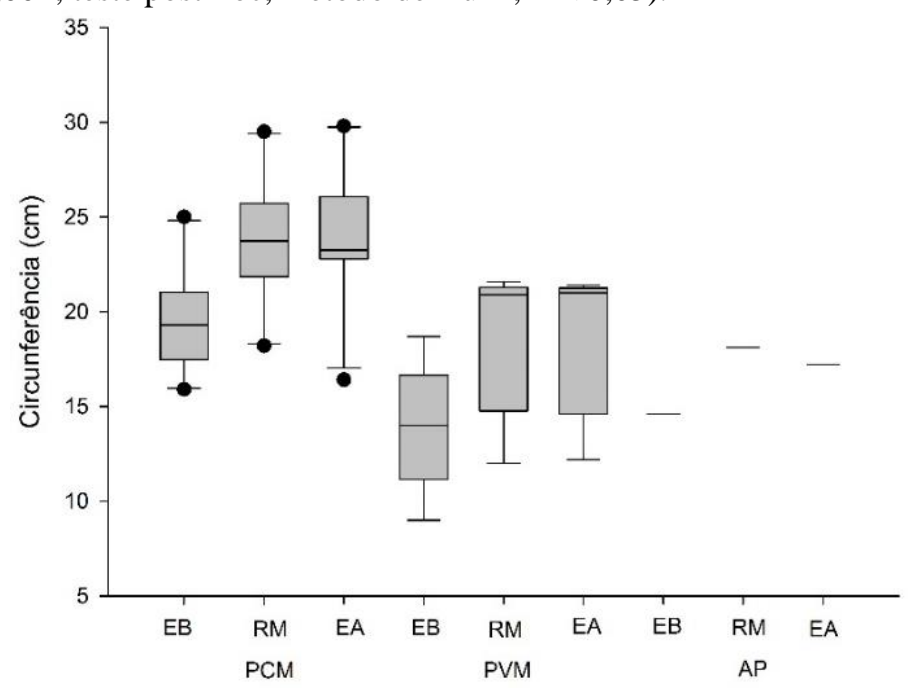


O tratamento polinização cruzada manual (PCM) resultou em frutos com maior quantidade de sementes no $1^{\circ} \mathrm{e}$ $3^{\text {o }}$ corte, sendo superado em número de sementes pela polinização por vibração manual (PVM) apenas no $2^{\circ}$ corte (Tabela 1). O fruto do tratamento de autopolinização (AP) apresentou sementes somente no $3^{\circ}$ corte do fruto (Tabela 1 ). De modo geral, o $1^{\circ}$ corte, próximo a extremidade basal, apresentou o menor número e o $3^{\circ}$ corte, próximo a extremidade apical, o maior número de sementes. No $1^{\circ}$ corte foram encontradas sementes em um único fruto do tratamento PCM (32 sementes). Os demais frutos, tanto do tratamento PCM como de PVM e AP, não apresentaram sementes. No $2^{\circ}$ corte os frutos do tratamento PCM tinham no máximo 95 e no mínimo 2 sementes e os frutos de PVM 149 e 0 sementes respectivamente. No $3^{\circ}$ corte os frutos do tratamento PCM tinham entre 54 e 135 sementes, e os frutos de PVM entre 32 e 174 sementes respectivamente.

Tabela 1: Médias e desvio padrão referente ao número de sementes nos frutos de cada tratamento. PVM=Polinização por vibração manual; PCM=Polinização cruzada manual; $\mathrm{AP}=$ Autopolinização

\begin{tabular}{cccc} 
Tratamentos & $\mathbf{1}^{\mathbf{0}}$ corte & $\mathbf{2}^{\mathbf{o}}$ corte & $\mathbf{3}^{\mathbf{o}}$ corte \\
\hline AP & 0 & 0 & 41 \\
PVM & $0 \pm 0$ & $37,8 \pm 63,06$ & $69,6 \pm 59,45$ \\
PCM & $3,2 \pm 10,12$ & $26,7 \pm 27,91$ & $103,4 \pm 21,79$ \\
\hline
\end{tabular}

No tratamento PCM, o número de sementes encontrado no $3^{\circ}$ corte foi estatisticamente maior do que os valores encontrados no $1^{\circ}$ e no $2^{\circ}$ corte (Kruskal Wallis One Way ANOVA: $\mathrm{H}=24,11, \mathrm{P}<0,001$; testes post-hoc, método de Dunn, $\mathrm{P}<0,05)$. Entretanto não houve diferença significativa entre o número de sementes encontrado no $1^{\circ}$ e $2^{\circ}$ corte (teste post-hoc, método de Dunn, $\mathrm{P}>0,05)$. No tratamento PVM houve diferença estatística apenas entre o $3^{\circ}$ e o $1^{\circ}$ corte (Kruskal Wallis One Way ANOVA: $\mathrm{H}=9,35, \mathrm{P}<0,009$; teste post-hoc, método de Dunn, $\mathrm{P}<0,05)$ (Figura 20).

Figura 6: Número de sementes no $1^{\circ}, 2^{\circ}$ e $3^{\circ}$ corte, respectivamente pertencentes a cada tratamento. PVM=Polinização por vibração manual; $\mathrm{PCM}=$ Polinização cruzada manual; $\mathrm{AP}=$ Autopolinização. Asterisco indica diferença significativa entre os cortes (Kruskal Wallis One Way ANOVA: $\mathrm{P}<0,001$; teste post-hoc, método de Dunn, $\mathrm{P}$ $<0,05)$

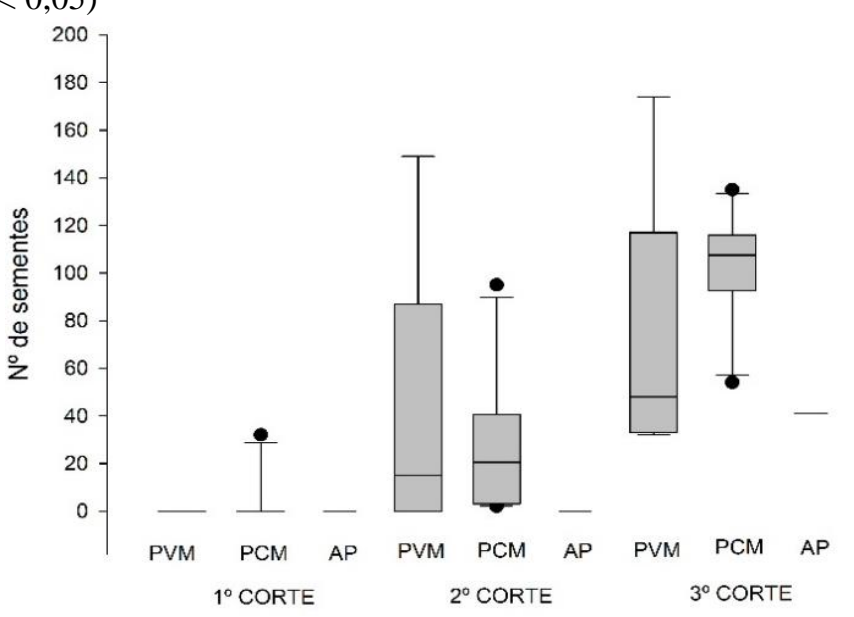

O tratamento de polinização cruzada manual (PCM) apresentou os maiores valores em relação a número de frutos produzidos, sendo que estes foram maiores, mais pesados e com maior número de sementes quando comparados com os demais tratamentos de polinização na cultura da berinjela. Talvez a baixa produção esteja relacionada com a temperatura, a qual permaneceu alta durante todo o experimento e considerando-se que a temperatura média ideal para o cultivo de berinjela é entre 18 e $25^{\circ} \mathrm{C}$ (SILVA et al, 2007) e da ausência de visita pelas abelhas, sendo que NunesSilva et al (2013) constatou que a Melipona fasciculata proporcionou um aumento na frutificação da berinjela em 29,5\% comparado com grupo controle (autofecundação) e também aumentou o peso do fruto em comparação com a autopolinização, já Bispo dos Santos (2008) mostrou que os frutos de berinjela produzidos foram mais pesados e maiores no canteiro aberto, seguidos daqueles oriundos dos polinizados por $M$. quadrifasciata quando comparados com a autopolinização.

Em geral, abelhas do gênero Melipona são mais adequadas para a polinização de solanáceas em casas de vegetação por serem capazes de realizar a polinização por vibração (NUNES-SILVA et al, 2010). No entanto, a utilização de Scaptotrigona sp., uma espécie que provavelmente não realiza polinização por vibração, se deu devido ao fato que suas colônias encontravam-se mais fortes e com maior número de indivíduos comparadas às colônias de M. subnitida, as quais estavam fracas após um período longo de seca que atingiu a região. Além disso, existe a possibilidade que a simples visita dessas abelhas contribui para um aumento na produção de frutos, como foi observado para a espécie de abelha sem ferrão Nannotrigona perilampoides, também incapaz de vibrar as flores, utilizada com sucesso para a polinização de tomates em casa de vegetação (CAUICH et al, 2004). Deste modo, são necessários mais estudos para determinar o verdadeiro potencial de Scaptotrigona sp. como polinizador de culturas em casa de vegetação.

\section{CONCLUSÕES}

A Scaptotrigona sp. não visitou as flores de berinjela, apesar de serem observadas abelhas nas folhas próximas as flores.

$\mathrm{O}$ tratamento de polinização cruzada manual (PCM) apresentou os maiores valores em relação a número de frutos produzidos, sendo que estes foram maiores, mais pesados e com maior número de sementes quando comparados com os demais tratamentos de polinização na cultura da berinjela.

\section{REFERÊNCIAS BIBLIOGRÁFICAS}

AMANO, K. Attempts to introduce stingless bees for the pollination of crops under greenhouse conditions in japan. 2000 .

BARTELLI, B. F. Adaptação e serviços de polinização de Melipona quadrifasciata Lepeletier, 1836 (Hymenoptera, Meliponina) em cultivo fechado de Lycopersicon esculentum Mill. (Solanaceae). Uberlândia/MG: Universidade Federal de Uberlândia, 2013. 53p.

BISPO DOS SANTOS, S. A. Polinização em culturas de manjericão, Ocimum basilicum L. (Lamiaceae), berinjela, Solanum melongena L. (Solanaceae) e tomate Lycopersicon 
esculentum (Solanaceae) por espécies de abelhas sem ferrão (Hymenoptera, Apidae, Meliponini). Ribeirão Preto/SP: Faculdade de Filosofia, Ciências e Letras de Ribeirão Preto/USP, 2008. 73p.

BOMFIM, I. G. A.; BEZERRA, A. D. M.; NUNES, A. C.; ARAGAO, F. A. S.; FREITAS, B. M. Adaptive and foraging behavior of two stingless bee species in greenhouse mini watermelon pollination. Sociobiology, v. 61, p. 502-509, 2014.

BUCHMANN, S.L.; HURLEY, J.P. A biophysical model for buzz pollination in angiosperms. Journal of Theoretical Biology, v. 72, p. 639-657, 1978.

CAUICH, O.; QUEZADA-EUÁN, J. J. G., MACIASMACIAS, J. O.; REYES-OREGEL, V.; MEDINAPERALTA, S.; PARRA-TABLA, V. Behavior and Pollination Efficiency of Nannotrigona perilampoides (Hymenoptera: Meliponini) on Greenhouse Tomatoes (Lycopersicon esculentum) in Subtropical México. Journal of Economic Entomology, v. 97, p. 475-481, 2004.

COOPER, P. D; SCHAFFER, W. M; BUCHMANN, S. L. Temperature Regulation of Honey Bees (Apis mellifera) foraging in the Sonoran Desert. Journal Experimental Biology, v. 114, p. 1-15, 1985.

CRUZ, D. de O.; CAMPOS, L. A. de O. Polinização por abelhas em cultivos protegidos. Revista Brasileira de Agrociência, v. 15, p. 5-10, 2009.

CRUZ, D. de O.; FREITAS, B. M.; SILVA, L. A. da; SILVA, E. M. S. da; BOMFIM, I. G. A. Pollination efficiency of the stingless bee Melipona subnitida on greenhouse sweet pepper Pesquisa agropecuária brasileira, v. 40, p. 1197-1201, 2005.

CRUZ, D.de O. Biologia floral e eficiência polinizadora das abelhas Apis mellifera L. (campo aberto) e Melipona quadrifasciata Lep. (ambiente protegido) na cultura da pimenta malagueta (Capsicum frutescens L.) em Minas Gerais, Brasil. Viçosa/MG: Universidade Federal de Viçosa, 2009. 102p.

DEL SARTO, M. C. L.; PERUQUETTI, R. C.; CAMPOS, L. A. O. Evaluation of the Neotropical Stingless Bee Melipona quadrifasciata (Hymenoptera: Apidae) as Pollinator of Greenhouse Tomatoes. Journal of Economic Entomology, v. 98, p. 260-266, 2005.

FREE, J.B. Insect pollination of crops. 2. ed. London: Academic Press, 1993.

HEARD, T. A. The role of stingless bees in crop pollination. Annu. Rev. Entomol, v. 44, p.183-206, 1999.

MACIEIRA, O. J. D.; PRONI, E. A. Capacidade de resistência a altas e baixas temperaturas em operárias de Scaptotrigona postica (Latreille) (Hymenoptera, Apidae) durante os períodos de verão e inverno. Revista Brasileira de Zoologia, v. 21, p. 893-896, 2004.

MEYRELlES, B. G. Polinização do tomate cereja por abelhas nativas em cultivo protegido. Viçosa/MG: Universidade Federal de Viçosa, 2013. 46p.
MICHENER, C. D. The Meliponini. In: VIT, P.; PEDRO, S. R. M.; ROUBIK, D. (Editores). Pot-Honey: A legacy of stingless bees. Springer. New York. 2013. 654 p.

MOURA, M. S. B. et al. Clima e água de chuva no semiárido. In: BRITO, L. T. de L.; MOURA, MS. B. de; GAMA, G. F. B. (Ed.). Potencialidades da água de chuva no semiárido brasileiro. Petrolina/PE: Embrapa Semiárido, 2007. p.37-59.

NASCIMENTO, W. M.; GOMES, E. M. L.; BATISTA, E. A.; FREITAS, R. A. Utilização de agentes polinizadores na produção de sementes de cenoura e pimenta doce em cultivo protegido. Horticultura Brasileira, v. 30, p.494-498, 2012.

NUNES-SILVA, P. Capacidade vibratória e polinização por vibração nas abelhas do gênero Melipona (Apidae, Meliponini) e Bombus (Apidae, Bombini). 2011. 133f. Tese (Doutorado em Ciências) - Universidade de São Paulo, Ribeirão Preto. 2011.

NUNES-SILVA, P.; HRNCIR, M.; IMPERATRIZFONSECA, V. L. A polinização por vibração. Oecologia Australis, v.14, p. 140-151, 2010.

NUNES-SILVA, P.; HRNCIR, M.; SILVA, C. I. da.; ROLDÃO, Y. S.; IMPERATRIZ-FONSECA, V. L. Stingless bees, Melipona fasciculata, as eficiente pollinators of eggplant (Solanum melongena) in greenhouses. Apidologie, 2013.

PALMA, G.; QUEZADA-EUÁN, J. J. G.; MELÉNDEZRAMIREZ, V.; IRIGOYEN, J.; VALDOVINOS-NUÑEZ, G. R.; REJÓN, M. Comparative Efficiency of Nannotrigona perilampoides, Bombus impatiens (Hymenoptera: Apoidea), and Mechanical Vibrationon Fruit Production of Enclosed Habanero Pepper. Journal of Economic Entomology, v. 101, p.132-138, 2008.

ROSELINO, A. C. Polinização em culturas de pimentão Capsicum annuum por Melipona quadrifasciata anthidioides e Melipona scutellaris e de morango - Fragaria $x$ ananassa por Scaptotrigona aff. depilis e Nannotrigona testaceicornis (Hymenoptera, Apidae, Meliponini). Ribeirão Preto, SP: Universidade de São Paulo, 2005. 105p

ROSELINO, A. C.; BISPO DOS SANTOS, S. A.; BEGO, L. R. Qualidade dos frutos de pimentão (Capsicum annuum L.) a partir de flores polinizadas por abelhas sem ferrão (Melipona quadrifasciata anthidioides Lepeletier 1836 e Melipona cutellaris Latreille 1811) sob cultivo protegido. Revista brasileira de Biociências, v. 8, p. 154-158, 2010.

SILVA, E. M. S. da; FREITAS, B. M.; SILVA, L. A. da; CRUZ, D. de O.; BOMFIM, I. G. A. Biologia floral do pimentão (Capsicum annuum) e a utilização da abelha jandaíra (Melipona subnitida Ducke) como polinizador em cultivo protegido. Revista Ciência Agronômica, v. 36, p. 386390, 2005.

SLAA, E. J.; SANCHEZ, L. A.; SANDI, M.; SALAZAR, W. A scientific note on the use of stingless bees for commercial pollination in enclosure. Apidologie, v. 31, p. 141-142, 2000.

TRANI, P. E.; TIVELI, S. W.; CARRIJO, O. A. Fertirrigação em hortaliças. 2. ed. rev. atual. Campinas: Instituto Agronômico. Série Tecnologia APTA. Boletim Técnico IAC, 2011. 51p. 